\title{
Study of Self-Concept, Classroom Environment and Parental Involvement as Predictors of Academic Achievement of Malayalam and English Medium Secondary Level Students
}

\author{
Samad Thazhe Vadakkayil ${ }^{1 *}$ and Mohd. Moshahid ${ }^{2}$
}

${ }^{1}$ Assistant Professor, Department of Education and Training, Maulana Azad National Urdu University, Gachibowli, Hyderabad, India ${ }^{2} \mathrm{HoD}$, Department of Education and Training, Maulana Azad National Urdu University, Gachibowli, Hyderabad, India

*Corresponding author: samadtvs@gmail.com

Received: $24-08-2020$

Revised: $19-10-2020$

Accepted: 28-11-2020

\begin{abstract}
The present study was conducted to find out the role of self-concept, classroom environment and parental involvement in the academic achievement of Malayalam and English medium secondary level students. The sample for the study was collected from various schools of Malabar region in the state of Kerala. Sample consists of 600 secondary school students who pursue education in Malayalam and English medium schools of which 300 are Malayalam medium students and 300 are English medium students. Different standardized tools were used to measure the self-concept, classroom environment and parental involvement; and the score of annual examination was taken as the indicator of academic achievement. Mean standard deviation, t-test, z-test and stepwise regression analysis were used for analyzing data. The study revealed that all the three variables significantly predict the academic achievement of the students for Malayalam and English medium groups. After classroom environment which is the highest predictor for both the groups, self-concept plays more important role in the prediction for Malayalam medium students whereas parental involvement plays more important role in the prediction for English medium students.
\end{abstract}

Keywords: Self-Concept, Classroom Environment, Parental Involvement, Academic Achievement and Secondary Level Students

It is a fact that people give very much importance for education. From the pre-primary stage to the higher studies stage, students, teachers, parents and the whole community are observing all the phases of education with much curiosity and they are working hard to obtain maximum success in all the subjects. Achievement is more often considered as a yard stick to measure the social status of the students. Academic achievement of the students in the school subjects may sometimes be capable of predicting their future.

Academic achievement of the students is influenced by several factors. From among these factors, Self-concept, classroom environment and parental involvement have great effect on achievement of the students in secondary stage. Self-concept (also called self construction, self-identity or self perspective) is a multidimensional construct that refers to an individual's perception of "Self" in relation to any number of characteristics such as academics and non academics. Self-concept is an internal model which comprises self assessment. To gain a better understanding of our self-concept, it is important that we examine our personality. An analysis of our thoughts and feelings about ourselves and the

\footnotetext{
How to cite this article: Vadakkayil, S.T. and Moshahid, M. (2020). Study of Self-Concept, Classroom Environment and Parental Involvement as Predictors of Academic Achievement of Malayalam and English Medium Secondary Level Students. Educational Quest: An Int. J. Edu. Appl. Soc. Sci., 11(4): 161-167.

Source of Support: None; Conflict of Interest: None
} 
world around us can assist us in this process. SelfConcept of the students represents the influence of the person on the process of education. The classroom environment represents the influence of the school on the process of education. The parental involvement represents the influence of the family on the process of education. So, these three variables can influence the academic achievement of the students from different angles.

Medium of instruction in the schools has nowadays become an index of social status and pride rather than the academic quality of the students. Many parents think that English medium schools can play a vital role in the academic success of the students while some others think that they can't cope up with the demands of English medium schools and hence they select Malayalam medium schools for their wards. At this juncture, the researchers think that it is significant to study what is the role of self-concept, classroom environment and parental involvement in the academic achievement of the students of Malayalam and English medium schools.

Many studies have been conducted to find out the role of self-concept, classroom environment and parental involvement in the academic achievement of students.

Caplin (2015) conducted a study on the self-concept of both white and Negro students studying in de facto segregated school and in desegregated schools with an aim to find out the relationship between self-concept and academic achievement of the students. The study revealed that students attending the de facto segregated school had less positive self-concepts. There was also a significant positive relationship between self-concept and academic achievement.

Alrehaili (2015) conducted a study to find out the relationship between academic achievement and self-concept in students with learning disabilities attending an elementary school in Western Saudi Arabia. Participants of the study were six elementary students with learning disabilities and a control group of 12 students without learning disabilities. Study came out with the result that the academic self-concept rather than the general self-concept is affected by learning disability status.

Mahakud (2016) conducted a study on self-concept and its relation to academic achievement. Single case design was followed for the study in which each participant's data were collected at the natural setting at both home and school setting. Sample of the study consisted of 60 higher secondary students from Delhi which was subdivided into 30 learning disabled and 30 skilled learners. The study found out that the children with learning disabilities were poor in their self-concept when compared to the skilled learners and consequently the children with learning disabilities were also poor in their academic performance in comparison to other students.

Stearns (2017) conducted an action research on the relationships between self-concept, teacher expectation and academic achievement of students as an analysis of social-emotional well being and its relation to their classroom performance. Sample of the study included 162 students and 8 teachers from McAlister Intermediate School, an elementary school in Suffield, Connecticut. The research concluded that the students with a higher sense of self-concept performed higher in the academic affairs.

Umar (2017) studied the effect of classroom environment on achievement in English as a Foreign Language (EFL) among secondary school students in Sudan. The results revealed significant differences between the achievements of both the groups as the experimental group which was taught under favorable classroom environment achieved better than the control group.

Javed and Asghar (2017) studied the association of classroom environment with the academic achievement of female secondary school students in Pakistan. Findings of the study showed a positive association between classroom environment and academic achievement of female students at secondary school level.

Anbalagan (2017) examined the impact of school environment on academic achievement of secondary school students. Sample of the study consisted of 160 students from higher secondary student in Madurai district. Findings of the study revealed that male students have better perception on school environment than the Female students.

Barksdale et al. (2017) examined the relationship between classroom climate and students' academic achievement in middle school in a large suburban school district in southeast Texas. Quantitative 
analysis of data discovered that there was not a significant mean difference between classroom climate and students' academic achievement. The qualitative analysis reached at the conclusion that a positive relationship did exist between the two variables.

Ezike (2018) investigated classroom environment and students' academic interest as correlates of achievement in Chemistry of senior secondary students. The study adopted the co relational design. Sample of the study was 208 senior secondary II students selected randomly from ten selected Public Secondary Schools in Ibadan Oyo State, Nigeria. Study found out significant relationships between each of the classroom environment and academic achievement, students' academic interest and achievement in Chemistry.

Castro et al. (2015) investigated the role of parental involvement in academic achievement through a meta-analysis of 37 studies in kindergarten, primary and secondary schools carried out between 2000 and 2013. Effect size estimations were obtained by transforming Fisher's correlation coefficient. The results revealed that the parental models focusing on general supervision of the children's learning activities are most linked to high achievement.

Seng et al. (2016) carried out a study to identify the level of parental involvement and the influence of parental involvement on children's academic achievement. The study involved 406 Form Five students in nine schools in Limbang, Sarawak, Malaysia. The findings showed that the levels of parental involvement are high and there is a significant influence of parental involvement on children's academic achievement.

Vijaya et al. (2016) conducted a study on parental involvement and academic achievement among high school students. Sample of the study which comprised of 300 high school students was collected from in and around Chennai. Parental Involvement scale prepared by the investigators was used to collect the data. The study revealed that the parental involvement has significant influence on students' academic achievement.

Parkash and Rani (2017) investigated the relationship of parental involvement and academic achievements of $7^{\text {th }}$ class students in Sirsa district of Haryana state. A sample of 160 children studying in $7^{\text {th }}$ standard has been taken randomly from 10 schools of Sirsa District in Haryana. The results showed a significant relationship between academic achievement of students and parental involvement in urban as well as rural areas.

\section{Objective of the Study}

The study had the following objective:

1. To find out and compare the predictability strength of self-concept, classroom environment and parental involvement on academic achievement for the Malayalam medium and English medium sample.

\section{Hypothesis}

1. Self-concept, classroom environment and parental involvement will not be found to be the significant predictors of academic achievement for Malayalam medium and English medium sample; and the two groups will show no significant difference with respect to their predictors or predictability strength.

\section{Methodology}

Survey method was used for the purpose of research. A sample of 600 students was collected using stratified random technique. Sample covered government, and private schools that follow the SCERT syllabus in Kerala. The sample covers male and female students. Children's Self-Concept Scale (CSCS-AS) standardized by Dr. S.P. Ahluwalia and Dr. Hari Shankar Singh, Classroom Environment Scale standardized by the investigators; and Parental Involvement Scale (TPIS) standardized by Chauhan and Arora were used to collect the data. Marks obtained by the students in the previous year annual examination (Std IX) was considered as the academic achievement indicator. Mean, SD, $\mathrm{t}$ - test, Z- Test, Pearson product moment correlation coefficient(r) and Step wise multiple regression analysis were used for analysis of the data.

\section{Analysis}

It is very clear from the Table 1 that all the coefficients of correlation of the predictive variables- self-concept, classroom environment and parental involvement with the criterion variable- academic achievement are positive and significant. The correlation 
coefficient between academic achievement and selfconcept is found to be 0.454 for Malayalam medium sample and 0.394 for English medium sample. All of these values of coefficient of correlation ( $\left.\mathrm{r}^{\prime} \mathrm{s}\right)$ are positive and significant at 0.05 level. This indicates that the students who get high level of self-concept will also obtain the high academic achievement. The correlation coefficient between academic achievement and classroom environment is found to be 0.581 for Malayalam medium sample and 0.621 for English medium sample. All of these values of coefficient of correlation ( $\left.\mathrm{r}^{\prime} \mathrm{s}\right)$ are positive and significant at 0.05 level.

Table 1: Correlation between the predictive variables and the criterion variable

\begin{tabular}{lll}
\hline \multirow{2}{*}{$\begin{array}{l}\text { Predictive } \\
\text { variables }\end{array}$} & \multicolumn{2}{c}{$\begin{array}{c}\text { Criterion Variable- Academic } \\
\text { Achievement }\end{array}$} \\
\cline { 2 - 3 } & $\begin{array}{l}\text { Malayalam medium } \\
\text { sample }(\mathrm{N}=300)\end{array}$ & $\begin{array}{l}\text { English medium } \\
\text { sample }(\mathrm{N}=300)\end{array}$ \\
\hline $\begin{array}{l}\text { Self-Concept } \\
\text { Classroom } \\
\text { environment }\end{array}$ & $0.454^{* *}$ & $0.394^{* *}$ \\
$\begin{array}{l}\text { Parental } \\
\text { involvement }\end{array}$ & $0.581^{* *}$ & $0.621^{* *}$ \\
\hline
\end{tabular}

$* *=p<0.05$.

This indicates that the students who possess high level of classroom environment will also obtain the high academic achievement. The correlation coefficient between academic achievement and parental involvement is found to be 0.459 for Malayalam medium sample and 0.463 for English medium sample. All of these values of coefficient of correlation ( $\left.\mathrm{r}^{\prime} \mathrm{s}\right)$ are positive and significant at 0.05 level. This indicates that the students who possess high level of parental involvement will also obtain the high academic achievement.

From Table 2, it can be clearly observed that all the predictive variables i.e., self-concept, classroom environment and parental involvement are found the significant predictors of the criterion variable i.e., academic achievement of the students of Malayalam medium sample. The predictability strength of all the three predictive variables on academic achievement of the students of Malayalam medium sample is $40.1 \%$. From among the predictive variables, classroom environment is found to be the most powerful predictor of which the predictability strength is found to be $33.8 \%$ which is significant at 0.001 level as the F-ratio is 151.837. The predictability strength of self-concept is $4.9 \%$ and the least predictability strength belongs to the parental involvement which is $1.4 \%$ only.

From Table 3, it can be clearly observed that all the predictive variables i.e., self-concept, classroom environment and parental involvement are found to be the significant predictors of the criterion variable i.e., academic achievement of the students for English medium sample. The predictability strength of all the three predictive variables on

Table 2: Stepwise regression analysis between the predictive variables and the criterion variable (Malayalam medium sample)

\begin{tabular}{|c|c|c|c|c|}
\hline \multirow{2}{*}{ Predictive variables and academic achievement } & \multirow{2}{*}{$\mathbf{R}^{2}$} & \multicolumn{3}{|c|}{ Change Statistics } \\
\hline & & $\mathbf{R}^{2}$ Change & F Change & $\mathrm{df}$ \\
\hline Classroom environment & 0.338 & 0.338 & $151.837^{* * *}$ & 298 \\
\hline Classroom environment and self-concept & 0.387 & 0.049 & $23.856^{* * *}$ & 297 \\
\hline Classroom environment, self-concept and parental involvement & 0.401 & 0.014 & $7.067^{* * *}$ & 296 \\
\hline
\end{tabular}

$* * *=p<0.001$.

Table 3: Stepwise regression analysis between the predictive variables and the criterion variable (English medium sample)

\begin{tabular}{llllll}
\hline \multirow{2}{*}{ Predictive variables and academic achievement } & \multirow{2}{*}{$\mathbf{R}^{2}$} & \multicolumn{4}{c}{ Change Statistics } \\
\cline { 3 - 6 } & & 0.386 & 0.386 & $187.437^{* * *}$ & 298 \\
Classroom environment & 0.440 & 0.054 & $28.457^{* * *}$ & 297 \\
Classroom environment and parental involvement & 0.451 & 0.011 & $5.910^{* * *}$ & 296 \\
Classroom environment, parental involvement and self-concept & & &
\end{tabular}

$* * *=p<0.001$. 
Table 4: Comparative strength of significant predictors of academic achievement in Malayalam medium and English medium sample

\begin{tabular}{llll}
\hline \multirow{2}{*}{ Predictive variables and academic achievement } & \multicolumn{2}{c}{ \% Shared common variance } & Z-value \\
\cline { 2 - 3 } & $\begin{array}{l}\text { Malayalam medium } \\
\text { sample }\end{array}$ & $\begin{array}{l}\text { English medium } \\
\text { sample }\end{array}$ & 2.729** \\
\hline Self-concept & 4.9 & 1.1 & 1.223 \\
Classroom environment & 33.8 & 38.6 & $2.719^{* *}$ \\
Parental involvement & 1.4 & 5.4 & \\
\hline
\end{tabular}

$* *=p<0.01$.

academic achievement of the English medium sample is $45.1 \%$. From among the predictive variables, classroom environment is found to be the most powerful predictor of which the predictability strength is $38.6 \%$ which is significant at 0.001 level. The predictability strength of parental involvement is $5.4 \%$ and the least predictability strength belongs to the self-concept which is $1.1 \%$ only.

From the analysis of the results presented in the Table 4, it is clear that the shared common variance of self-concept in the academic achievement of Malayalam medium secondary level students is 4.9 when it is 1.1 for the academic achievement of English medium secondary level students. Result of the $\mathrm{z}$-test conducted to find the difference between these two percentages revealed a $\mathrm{Z}$ value of 2.729 which is significant at 0.01 level. So, it can be understood that self-concept plays more significant role in determining the academic achievement of Malayalam medium secondary level students when compared to the English medium secondary level students.

The second significant predictor i.e. classroom environment occupies a shared common variance of $33.8 \%$ for Malayalam medium secondary level students when it is $38.6 \%$ for English medium secondary level students. Result of the z-test conducted to find the difference between these two percentages revealed a $Z$ value of 1.223 which is not significant at any level. So, it can be understood that classroom environment plays equal significant role in determining the academic achievement of Malayalam and English medium secondary level students.

Regarding the third predictor i.e. parental involvement, it is clear from the Table 4 that the shared common variance of parental involvement in the academic achievement of Malayalam medium secondary level students is 1.4 when it is 5.4 for the academic achievement of English medium secondary level students. Result of the z-test conducted to find the difference between these two percentages revealed a $\mathrm{Z}$ value of 2.719 which is significant at 0.01 level. So, it can be understood that parental involvement plays more significant role in determining the academic achievement of English medium secondary level students when compared to the Malayalam medium secondary level students.

\section{Findings of the Study}

1. Classroom environment, self-concept and parental involvement are found to be the significant predictors of academic achievement for the Malayalam medium sample and they occupy the predictability strength of $40.1 \%$.

2. For the Malayalam medium sample, classroom environment shares the largest predictable variance which is $33.8 \%$; and selfconcept and parental involvement follow it with $4.9 \%$ and $1.4 \%$ respectively.

3. Classroom environment, parental involvement and self-concept are found to be the significant predictors of academic achievement for the English medium sample and they occupy the predictability strength of $45.1 \%$.

4. For the English medium sample, classroom environment shares the largest predictable variance which is $38.6 \%$; and parental involvement and self-concept follow it with $5.4 \%$ and $1.1 \%$ respectively.

5. All the three predictors significantly predict the academic achievement of the students for both the groups. After classroom environment 
which is the highest predictor for both the groups, self-concept plays more important role in the prediction for Malayalam medium students whereas parental involvement plays more important role in the prediction for English medium students.

\section{CONCLUSION AND EDUCATIONAL IMPLICATIONS}

From the above findings, the researchers could arrive at the conclusion that the academic achievement of Malayalam and IEnglish medium secondary level students is influenced by their self-concept, classroom environment and parental involvement. From among the three predictors, classroom environment is found to be the largest one in both the groups. Self-Concept of the Malayalam medium students predicts their achievement more than that of their parental involvement. Parental involvement of English medium students predicts their academic achievement more than what their self-concept does. This clearly indicates that the classroom environment in both Malayalam and English medium schools provides good learning atmosphere. In Malayalam medium schools, students' self-concept predicts their academic achievement more and this indicates that better results can be expected if programs are carried out to develop better self-concept of the students. In English medium schools, parental involvement acts as better predictor and hence more programs to ensure parental involvement will bring out better results in academic achievement.

As the present study highlights the role of classroom environment in predicting the academic achievement in both the medium schools, careful attention should be given to provide the best academic atmosphere in the classrooms. A classroom environment which utilizes advanced technology and ensures free and safe learning atmosphere will lead the students to all heights of success. Teachers and peer students have a lot of influence on the education of the students. Every single teacher, heads of schools, PTA and the government should act vigilantly to ensure that each and every child gets suitable learning atmosphere in the school. Being a significant predictor of academic achievement, self-concept of the students also should be treated with much importance. Measures to develop better self-concept must be carried out regularly. The students should be frequently reminded of their duties and rights; and the ways should be explored to achieve their dreams. More motivation sessions should be arranged so that the students will be provided with many opportunities to find out ideal self which will lead to formation of better self-concept. Parents are the second teachers for their students and hence parental involvement in the education of the students should be encouraged. A strong bond between the parents and students will make the learning process easier. Moral and mental support of the parents pass huge amount of energy to the students. Adequate training programs to parents will help them handle different situations with their children. Parents who are aware of the needs of their wards can help them a lot in achieving their goals. Briefly, all of these three predictors of academic achievement of the secondary level students need the attention of the students, teachers, parents and the social activists. All should explore the ways how they can support the students for obtaining high academic achievement focusing particularly on the classroom environment, self-concept and the parental involvement.

\section{REFERENCES}

Anbalagan, S. 2017. Impact of school environment on academic achievement of secondary school students in Madurai district. International Journal of Applied Research 3(5): 732-737.

Barksdale, Christopher \& Peters, Michelle \& Corrales, Antonio. 2015. Middle school students' perceptions of classroom climate and its relationship to achievement. Educational Studies, pp. 1-24. 10.1080/03055698.2019.1664411.

Castro, M., Expósito-Casas, E., López-Martín, E., Lizasoain, L., NavarroAsencio, E. and Gaviria, J.L. 2015. Parental involvement on student achievement: A meta-analysis. Educational Research Review, 14: 33-46.

Morris D. Caplin. 1969. The Relationship between Self-concept and Academic Achievement, The Journal of Experimental Education, 37(3): 13-16.

Ezike, B.U. 2018. Classroom environment and academic interest as correlates of achievement in Senior Secondary School Chemistry in Ibadan South West Local Government Area, Oyo State, Nigeria. Global Journal of Educational Research, 17: 61-71.

Mahakud, G.C. and Joshi, R. 2016. Self-concept and its relation to academic achievement. International Journal of Education and Psychological Research (IJEPR) 5(1): 34-39.

Parkash, J. and Rani, S. 2017. A study on relationship of parental involvement and academic achievements of 7 th 
class students in Sirsa district of Haryana state. Journal of Marketing Strategy (JMS), 5(3).

Seng, N.L, Hanafi, Z. and Taslikhan, M. 2016. Influence of parental involvement on academic achievement. International Journal of Advanced Education and Research, 1(4): 01-04.

Stearns, K.E. 2017. Unpublished Certificate of Advanced Study Thesis, Sacred Heart University, Fairfield, CT. Retrieved from http://digitalcommons.sacredheart.edu/ edl/19
Umar, A.M. 2017. The Effect of Classroom Environment on Achievement in English as a Foreign Language (EFL): A Case Study of Secondary School Students in Gezira State: Sudan. World Journal of English Language, 7(4): 01-09.

Vijaya, S., Vijaya R. and Rajeshkumar, M. 2016. Parental involvement and academic achievement among high school students. Review of Research, 5(12): 12-17. 
